\title{
Distribuição do sistema radicular de aceroleiras
}

\section{Distribution of roots of west indian cherry plants}

\author{
Ives Massanori Murata ${ }^{1}$; Neusa Maria Colauto Stenzel ${ }^{2}$; Aline Fagote Paulino ${ }^{1}$; \\ Cristina Célia Krawulski ${ }^{1}$; Carmen Silvia Vieira Janeiro Neves ${ }^{3}$; \\ Cristiane de Conti Medina ${ }^{3 *}$; Marcelo Sumiya ${ }^{4}$; Marcos Yutaka Yano ${ }^{4}$
}

\begin{abstract}
Resumo
O conhecimento sobre a quantidade e a distribuição das raízes das plantas é fundamental para a produção agrícola, pois auxilia na tomada de decisões relativas ao manejo do solo e à localização da irrigação e de fertilizantes. O presente trabalho teve como objetivo avaliar e comparar a quantidade e a distribuição das raízes de aceroleiras (Malpighia emarginata D.C.), por meio de imagens digitais, no método da trincheira, em Latossolo Vermelho distroférrico, em Londrina, Paraná. Foram avaliados porta-enxertos obtidos de sementes e enxertados com os clones Camb-6, Cia-2 e Cia-3. O espaçamento de plantio utilizado foi de $4 \times 4 \mathrm{~m}$ e as plantas estavam com 5 anos de idade. Não houve diferença estatística quanto à quantidade de raízes entre as plantas, tanto na linha, quanto na entrelinha de plantio, bem como no total de raízes (linha + entrelinha). A distância e a profundidade efetivas (até onde localizamse $80 \%$ das raízes) na linha e na entrelinha não mostraram diferença estatística entre as plantas avaliadas. A profundidade efetiva para os porta-enxertos com os clones Camb-6, Cia-2 e Cia-3 foi de 0,62 m na linha de plantio e $0,65 \mathrm{~m}$ na entrelinha.
\end{abstract}

Palavras-Chave: Malpighia emarginata, raízes, método da trincheira

\begin{abstract}
The knowledge of the amount and distribution of plant roots is essential to all crops because it gives useful information to irrigation, soil management and amendment. The aim of this research was to quantify and analyze the root distribution of West Indian cherry (Malpighia emarginata D.C.) through digital images using the trench profile method in a clayey oxisol in Londrina, State of Paraná (Brazil). The orchard was planted in a $4 \times 4$ spacing and was 5 years old. There were evaluated three rootstocks obtained by seeds and grafted on Camb- 6 , Cia- 2 and Cia- 3 genotypes. There was no difference regarding the amount of roots in row and inter-rows as well. The effective distance and depth (distance and depth until there are located $80 \%$ of the roots), in the row and inter-row had no difference regarding the evaluated plants. The effective depth of roots were $0.62 \mathrm{~m}$ in the row, and $0.65 \mathrm{~m}$ in the inter-row.
\end{abstract}

Key Words: Malpighia emarginata, root, profile wall method

\footnotetext{
1 Eng. Agr., Ms., Pós-Graduando em Agronomia, Universidade Estadual de Londrina. Bolsista CAPES.

2 Enga. Agra., Ms., Pesquisadora do Instituto Agronômico do Paraná - IAPAR.

3 Enga. Agra., Dra., Professora do Dep. de Agronomia, Universidade Estadual de Londrina. C.P. 6001, CEP 86.051-990, Londrina, PR., Tel. 43 3371-4555, Email: csvjneve@uel.br; medina@uel.br

4 Acadêmico de Agronomia, Universidade Estadual de Londrina.

* Autor para correspondência.
} 


\section{Introdução}

A aceroleira (Malpighia emarginata D.C.) é um arbusto frutífero originário da América Tropical, pertencente à família Malpighiaceae. Sua copa, geralmente, é proporcional à altura, com pequeno tronco único, ramos densos e espalhados, e raiz pivotante ou axial (ALVES; MENEZES, 1995). A partir de 1990, seu cultivo no Brasil tornou-se expressivo, principalmente, por apresentar alto teor de ácido ascórbico em seus frutos (ARAÚJO; MINAMI, 1994). A exploração comercial da acerola está concentrada nas regiões Norte e Nordeste (BLISKA; LEITE, 1995). Na região Sul, o Paraná apresenta-se como o principal produtor, sendo que o cultivo desta fruteira tem sido uma das alternativas de diversificação para as pequenas propriedades (STENZEL; MOTTER, 1995).

As raízes constituem uma parte da planta de extrema importância, pois, além de extrair água e nutrientes, fixam a planta ao solo (LIBARDI; LIER, 1999). Estudos referentes à quantidade, extensão e distribuição das raízes, além de serem importantes na seleção dos materiais no melhoramento genético, consistem em informação fundamental para se determinar técnicas culturais, tais como: espaçamento de plantio, manejo do solo, adubação e irrigação localizada (CASTLE et al., 1989).

Segundo Barber (1995), é desejável, sob o aspecto da absorção de nutrientes, que as plantas apresentem um amplo sistema radicular. As raízes das plantas perenes podem variar desde raízes finas e fibrosas até raízes grossas, podendo apresentar variações em função da espécie e cultivar, das características químicas e físicas do solo, dos tratos culturais, das condições fitossanitárias e da idade da planta.

Considerando a importância sobre informações do sistema radicular para se determinar manejos, tratos culturais e seleção de material genético e, sobretudo, devido à escassez dos trabalhos científicos sobre $\mathrm{o}$ assunto relacionados à cultura da aceroleira, $\mathrm{o}$ presente trabalho teve como objetivo avaliar e comparar a quantidade e a distribuição das raízes dos porta-enxertos de três clones de aceroleira, nas condições do Norte do Paraná.

\section{Material e Métodos}

O trabalho foi realizado em um pomar formado por uma coleção de aceroleiras localizado na Estação Experimental do Instituto Agronômico do Paraná, no município de Londrina, PR com coordenadas $23^{\circ} 23^{\prime} \mathrm{S}$ e $51^{\circ} 11^{\prime} \mathrm{W}$. O clima da região, segundo a classificação de Köppen, é do tipo Cfa, subtropical úmido, com chuvas em todas as estações, podendo ocorrer seca no período de inverno (CORRÊA; GODOY; BERNARDES, 1982). O solo foi classificado como Latossolo Vermelho distroférrico (EMBRAPA, 1999).

Foram avaliadas plantas de três clones de acerola selecionados pelo programa de melhoramento genético do IAPAR: Camb-6, Cia-2 e Cia-3, por apresentarem características agronômicas promissoras, como alta produtividade e altos teores de ácido ascórbico (SCHOLZ; STENZEL, 1996). As plantas foram propagadas por enxertia em porta-enxertos péfrancos, cujas sementes foram obtidas em pomares comerciais. O espaçamento utilizado foi de 4 x $4 \mathrm{~m}$ e as plantas tinham 5 anos de idade por ocasião da avaliação das raízes.

A avaliação foi realizada entre os meses de outubro e novembro de 2000, período em que o sistema radicular encontrava-se em pleno desenvolvimento, pois as plantas estavam em fase de desenvolvimento vegetativo e início da safra.

O sistema radicular das plantas foi estudado através do método da trincheira ou perfil (BÖHM, 1979), com três repetições (trincheiras) inteiramente ao acaso para cada tratamento (clone). As trincheiras foram abertas a partir de $0,10 \mathrm{~m}$ do tronco de cada planta nas direções perpendicular (entrelinha) e paralela à linha (linha) de plantio, com 2,00 $\mathrm{m}$ de comprimento nos dois sentidos (até metade do espaçamento de plantio) e 1,00 $\mathrm{m}$ de profundidade. Após a abertura das trincheiras, as paredes dos per- 
fis foram niveladas, e as raízes foram expostas com escarificador em forma de rolo, composto de pregos sem cabeça. Posteriormente as raízes foram coloridas com tinta látex branca, com a finalidade de se obter maior contraste entre o solo e as raízes. $\mathrm{Na}$ parede da trincheira foi afixada uma moldura de madeira, dividida por fios de nylon em quadrículas de 0,25 por 0,25 m (CINTRA; NEVES, 1996).

Foram estudadas as distâncias (a partir do tronco) de: $0,00-0,25 ; 0,25-0,50 ; 0,50-0,75 ; 0,75-1,00$; $1,25-1,50 ; 1,50-1,75$; e 1,75-2,00 m. Já as profundidades foram de: $0,00-0,25 ; 0,25-0,50 ; 0,50-0,75 \mathrm{e}$ 0,75-1,00 m. Imagens das raízes de cada quadrícula foram obtidas através de câmera fotográfica digital. Com o programa SIARCS (Sistema Integrado para Análise de Raízes e Cobertura do Solo) (CRESTANA et al., 1994), as imagens foram processadas para determinações de área $\left(\mathrm{cm}^{2}\right)$ e comprimento $(\mathrm{cm})$ das raízes em cada quadrícula.

Os dados de área e comprimento de raízes de cada quadrícula foram agrupados por perfil, por distância do tronco e por profundidade para cada clone. Foram calculadas também as porcentagens de raízes por profundidade e por distância do tronco e porcentagens acumuladas de raízes, para a determinação das profundidades e das distâncias efetivas, ou seja, a profundidade e a distância até onde estão concentradas $80 \%$ das raízes das plantas a partir do tronco (KLAR, 1991). Quando não se atingiu $80 \%$ exatamente nas profundidades e distâncias estudadas, foram feitos cálculos através de regra de três simples.

O delineamento experimental utilizado foi o de blocos ao acaso, com três tratamentos (clones de aceroleiras) e três repetições (trincheiras). Para comparação entre os clones para médias da quantidade de raízes nas profundidades estudadas e totais da linha e da entrelinha de plantio; e para profundidades e distâncias efetivas, realizou-se análise de variância, complementada pelo teste de Tukey no nível de $5 \%$ de significância.

Amostras de solo para análises químicas foram coletadas nos perfis da linha e da entrelinha de plan- tio de todas as trincheiras a $1,00 \mathrm{~m}$ do tronco das plantas, com o intuito de caracterizar a fertilidade do solo no local onde se encontra a maior parte do sistema radicular. As amostras foram coletadas em quatro profundidades: $0,00-0,10 ; 0,10-0,25 ; 0,25-$ 0,50 e 0,50-0,75 m, sendo que as amostras da linha e da entrelinha foram homogeneizadas por profundidade. As análises químicas do solo foram realizadas de acordo com Pavan et al. (1992). Para a análise granulométrica, as amostras foram coletadas nas mesmas distâncias e profundidades, porém foram homogeneizadas em uma única amostra. Apresentaram a seguinte distribuição por tamanho de partículas: $710 \mathrm{~g} \mathrm{~kg}^{-1}$ de argila, $130 \mathrm{~g} \mathrm{~kg}^{-1}$ de silte e $160 \mathrm{~g} \mathrm{~kg}^{-1}$ de areia.

\section{Resultados e Discussão}

As condições químicas do solo (Tabela 1) encontravam-se adequadas para o desenvolvimento das raízes, pois até a profundidade de $0,25 \mathrm{~m}$ todos os elementos tinham níveis de médio a alto. A partir desta profundidade, apenas o $\mathrm{P}$ se encontrava no nível baixo, enquanto que o $\mathrm{Ca}$ apresentou-se baixo apenas a partir de 0,50 m (PARANÁ, 1989).

Tabela 1 - Características químicas do solo na área experimental em quatro profundidades. Londrina PR, 2000.

\begin{tabular}{cccccccc}
\hline Prof. (m) & $\mathrm{Ca}$ & $\mathrm{Mg}$ & $\begin{array}{c}\mathrm{K} \\
\mathrm{H}+\mathrm{Al}\end{array}$ & $\begin{array}{c}\mathrm{pH} \\
\mathrm{CaCl}_{2}\end{array}$ & $\begin{array}{c}\mathrm{P} \\
\mathrm{mg} \mathrm{dm}^{-3}\end{array}$ & $\begin{array}{c}\mathrm{MO} \\
\mathrm{g} \mathrm{dm}^{-3}\end{array}$ \\
\hline $0,00-0,10$ & 25,8 & 13,9 & 7,8 & 85,3 & 4,33 & 18,58 & 19,50 \\
$0,10-0,25$ & 28,0 & 12,1 & 4,3 & 78,6 & 4,28 & 8,58 & 16,00 \\
$0,25-0,50$ & 24,9 & 9,2 & 2,1 & 64,9 & 4,20 & 1,80 & 9,39 \\
$0,50-0,75$ & 18,8 & 9,7 & 1,2 & 91,9 & 4,18 & 1,60 & 9,20 \\
\hline
\end{tabular}

Para a quantidade de raízes apresentadas pelas aceroleiras estudadas, na Tabela 2 pode-se observar que não houve diferença significativa em relação ao comprimento total de raízes da linha, da entrelinha e do total geral (linha + entrelinha) entre os três clones, indicando a boa adaptação destes genótipos às con- 
dições locais, o que explica a boa produção encontrada por Scholz e Stenzel (1996) para essas plantas.

Tabela 2 - Comprimentos de raízes de clones de aceroleira na linha de plantio, na entrelinha e no total (linha + entrelinha). Londrina - PR, 2000.

\begin{tabular}{|c|c|c|c|}
\hline \multirow[b]{2}{*}{ Clones } & \multicolumn{3}{|c|}{ Comprimento de raízes $(\mathrm{cm})$} \\
\hline & Linha & Entrelinha & Total \\
\hline Cia-2 & $1.653,36 \mathrm{a}$ & $1.938,16 \mathrm{a}$ & $3.591,54 \mathrm{a}^{*}$ \\
\hline Cia-3 & $2.016,18 \mathrm{a}$ & $1.546,70 \mathrm{a}$ & $3.562,88 \mathrm{a}$ \\
\hline Camb-6 & 822,82 a & $1.341,73 \mathrm{a}$ & $2.164,55 \mathrm{a}$ \\
\hline $\mathrm{CV}(\%)$ & 41,11 & 21,30 & 19,48 \\
\hline D.M.S. & $1.542,67$ & 858,90 & $1.516,20$ \\
\hline
\end{tabular}

*Médias seguidas da mesma letra na vertical, não diferem a 5 $\%$ de significância pelo teste de Tukey.

Neves et al. (2001), que avaliaram o sistema radicular dos cultivares de aceroleira 'Lígia', 'Dominga' e 'Natália' no mesmo tipo de solo, encontraram valores menores de comprimento de raízes do que os obtidos para o presente trabalho. Esta diferença pode ser atribuída ao espaçamento de plantio de $2,0 \times 2,0 \mathrm{~m}$ naquele trabalho, enquanto que no presente se usou 4,0 x 4,0 m. Além disso, apesar daquele trabalho ter sido feito no mesmo tipo de solo, o nível do nutriente $\mathrm{P}$ encontrava-se baixo em todas as profundidades. A variabilidade genética também pode ter contribuído para as diferenças na quantidade de raízes entre os dois ensaios. Segundo Castle e Krezdorn (1977), apesar da importância dos fatores como tipo de solo, espaçamento de plantio, concentração de nutrientes e teor de água no ambiente radicular, o componente genético exerce grande influência no desenvolvimento do sistema radicular das plantas.

A Figura 1 apresenta a área de raízes por profundidade na linha de plantio. Observa-se que também não houve diferença estatística entre os clones em todas as profundidades estudadas.

$\mathrm{Na}$ entrelinha (Figura 2), nota-se que o clone Cia2 destacou-se por apresentar maior área de raízes, embora não significativa, a partir de $0,50 \mathrm{~m}$ de profundidade. Esta característica pode ser favorável à planta, pois, segundo Gardner (1981), as raízes devem estender-se suficientemente em profundidade no solo, de tal modo que a qualquer déficit de água, quando a evapotranspiração exceder a precipitação, a água possa ser suprida pela maior exploração da zona radicular.

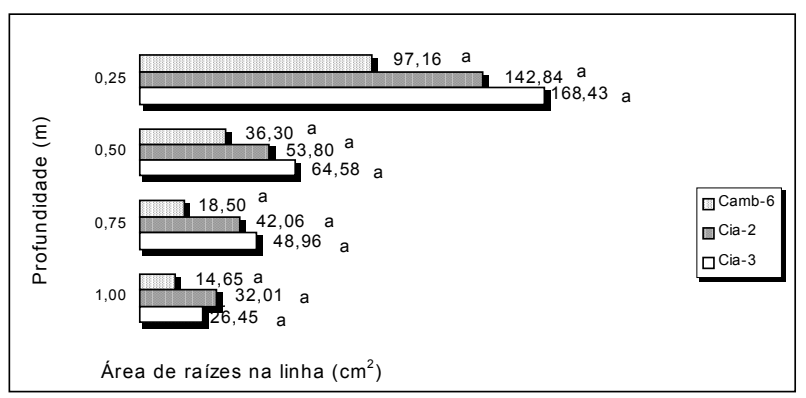

* Médias seguidas da mesma letra, na mesma profundidade, não diferem pelo teste de Tukey a 5\%.

Figura 1 - Distribuição de raízes de clones de acerola por profundidade na linha de plantio. Londrina-PR, 2000.

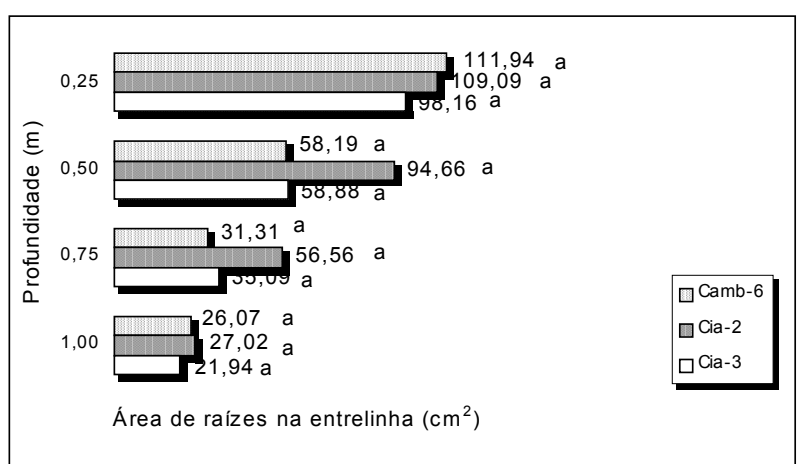

*Médias seguidas da mesma letra, na mesma profundidade, não diferem pelo teste de Tukey a 5\%.

Figura 2 - Distribuição de raízes de clones de acerola por profundidade na entrelinha de plantio. Londrina-PR, 2000.

A ausência de diferenças significativas entre os clones para a quantidade de raízes é decorrente, provavelmente, da grande variabilidade do ambiente radicular, elevando a diferença mínima exigida para a significância. Esta variabilidade ocorre devido à heterogeneidade do solo, pois as raízes crescem ou se ramificam em locais propícios ao seu desenvolvimento, desviando de zonas menos favorá- 
veis, seguindo caminhos de menor resistência em fendas e canais formados pela fauna e matéria orgânica do solo (ATKINSON, 1980). Além disso, esta heterogeneidade pode ser atribuída também, ao fato dos porta-enxertos terem sido propagados por sementes, pois, segundo Araújo e Minami (1994), para aceroleiras, mesmo que as sementes sejam provenientes de pomar homogêneo, as plantas provenientes de sementes podem apresentar segregação.

Na Tabela 3 encontram-se os resultados das profundidades efetivas, calculadas para os clones estudados, na linha e entrelinha de plantio. Nota-se que não houve diferença significativa das profundidades efetivas entre os clones, tanto na linha como na entrelinha de plantio, com valores de 0,59 a $0,66 \mathrm{~m}$. Os valores encontrados são próximos aos obtidos por Neves et al. (2001), onde os três cultivares: 'Dominga', 'Lígia' e 'Natália', propagados por estaquia e avaliadas no mesmo tipo de solo, apresentaram profundidade efetiva de: 0,$53 ; 0,69$ e 0,50 na linha, e 0,$55 ; 0,61$ e $0,61 \mathrm{~m}$ na entrelinha de plantio, respectivamente.

Tabela 3 - Profundidades e distâncias efetivas dos sistema radicular de aceroleiras na linha e entrelinha de plantio (média de três repetições). Londrina-PR, 2000.

\begin{tabular}{lccccc}
\hline \multirow{2}{*}{ Clones } & \multicolumn{2}{c}{ Profundidade efetiva } & & \multicolumn{2}{c}{ Distância efetiva } \\
\cline { 2 - 3 } \cline { 6 - 6 } & Linha & Entrelinha & & Linha & Entrelinha \\
\hline Camb-6 & $0,59 \mathrm{a}$ & $0,62 \mathrm{a}$ & & $1,53 \mathrm{a}$ & $1,50 \mathrm{a}$ \\
Cia-2 & $0,67 \mathrm{a}$ & $0,66 \mathrm{a}$ & & $1,49 \mathrm{a}$ & $1,43 \mathrm{a}$ \\
Cia-3 & $0,60 \mathrm{a}$ & $0,66 \mathrm{a}$ & & $1,57 \mathrm{a}$ & $1,46 \mathrm{a}$ \\
\hline C.V. (\%) & 15,67 & 11,97 & & 5,72 & 9,17 \\
D.M.S. & 0,25 & 0,39 & & 0,28 & 0,22
\end{tabular}

*Médias seguidas da mesma letra na vertical, não diferem no nível de $5 \%$ pelo teste de Tukey.

Diferindo do observado no presente trabalho, Montenegro, Bandeira e Lima (2001), comparando dois regimes de irrigação em um solo Podzólico Vermelho-Amarelo distrófico, verificaram que $80 \%$ do sistema radicular de clones de acerola encontrava-se até 0,20 a $0,40 \mathrm{~m}$; nestas profundidades, detectaram redução de 5 a 8 vezes no percentual de raízes finas em relação à concentração de raízes na camada de 0,00 a 0,20 m. Esta característica da distribuição do sistema radicular, provavelmente, se deve àquele tipo de solo, que apresenta uma camada de impedimento físico devido ao horizonte B ser mais argiloso. Tal situação se assemelha ao encontrado por Pace e Araújo (1986), no mesmo tipo de solo, para raízes de citros.

A distância efetiva na linha e na entrelinha de plantio, para os clones Camb-6, Cia-2 e Cia-3, variou de 1,43 a 1,57 (Tabela 3). Neves et al. (2001) encontraram valores em torno de $1,50 \mathrm{~m}$ na entrelinha e 0,75 $\mathrm{m}$ na linha de plantio, para todos os cultivares avaliados naquele estudo, com espaçamento de 2,00 m na linha. No presente trabalho, a distância efetiva encontrada na linha foi o dobro daquele trabalho, podendose atribuir esses resultados, também, ao espaçamento, que na linha de plantio foi de 4,00 m, ou seja, 2,00 m a mais que o usado por Neves et al. (2001). Sobre esse assunto, Kaufmann, Boswell e Lewis (1972) observaram que a distribuição radicular foi afetada pelo espaçamento das árvores, devido à competição das raízes por água e nutrientes.

\section{Conclusões}

Para as condições do presente ensaio, conclui-se que:

Não existe diferença entre as plantas avaliadas para quantidade de raízes na linha, na entrelinha e no total.

A profundidade efetiva das raízes para as plantas estudadas varia de 0,59 a $0,66 \mathrm{~m}$.

\section{Agradecimentos}

Os autores agradecem a Ulisses B. Albino pelo apoio na coleta dos dados. 


\section{Referências}

ALVES, R. E.; MENEZES, J. B. Botânica da aceroleira. In: SÃO JOSÉ, A.R.; ALVES, R.E. (Ed.). Acerola no Brasil: produção e mercado. Vitória da Conquista: UESB, 1995. p.7-14.

ARAÚJO, P. S. R.; MINAMI, K. Acerola. Campinas: Fundação Cargill, 1994.

ATKINSON, D. The distribution and effectiveness of the roots of tree crops. Horticultural Reviews, New York, v.2, p.424-490, 1980.

BARBER, S. A. Soil nutrient bioavailability: a mechanistic approach. New York: John Wiley \& Sons, 1995.

BLISKA, F. M. M.; LEITE, R. S. F. Aspectos econômicos e de mercado. In: SÃO JOSÉ, A. R.; ALVES, R. E. Acerola no Brasil: produção e mercado. Vitória da Conquista: UESB, 1995. p.107-123.

BÖHM, W. Methods of studying root systems. Berlin: Springer-Verlag, 1979.

CASTLE, W. S. et al. Rootstocks for Florida citrus: rootstock selection the first step to successes. Gainesville: University of Florida, 1989.

CASTLE, W. S.; KREZDORN, A. H. Soil water use and apparent root efficiencies of citrus trees on four rootstocks. Journal of the American Society for Horticultural Science, Gainesville, v.102, n.4, p.403-406, 1977.

CINTRA, F. L. D.; NEVES, C. S. V. J. Aspectos metodológicos do estudo do sistema radicular de plantas perenes através de imagens. Boletim Informativo da Sociedade Brasileira de Ciência do Solo, Campinas, v.21, n.3, p.91-94, 1996.

CORREAA, A. R.; GODOY, H.; BERNARDES, R. L. M. Características climáticas de Londrina. 2.ed. Londrina: IAPAR, 1982. (Circular Técnica, 5).

CRESTANA, S. et al. Avaliação da distribuição de raízes no solo auxiliada por processamento de imagens digitais. Revista Brasileira de Ciência do Solo, Campinas, v.18, p.365-371, 1994.

EMBRAPA. Solos: sistema brasileiro de classificação de solos. Rio de Janeiro: Centro Nacional de Pesquisa de Solos, 1999.

GARDNER, W.R. Crescimento da raiz e déficit de água. In: SIMPÓSIO SOBRE AMBIENTE RADICULAR. 1., 1981, Londrina. Anais ... Londrina: IAPAR/ EMBRAPA/ CNPq, 1981. p.19.
KAUFMANN, M. R.; BOSWELL, S. B.; LEWIS, L. N. Effect of tree spacing on root distribution of 9-year old Washington Navel Orange. Journal of the American Society Horticultural Science, Gainesville, v.97, n.2, p.204-206, 1972.

KLAR, A. E. Irrigação: freqüência e quantidade de aplicação. São Paulo: Nobel. 1991.

LIBARDI, P. L.; LIER, Q. J. V. Atuação dos fatores físicos do solo no desenvolvimento do sistema radicular. In: WORKSHOP SOBRE SISTEMA RADICULAR: METODOLOGIAS E ESTUDO DE CASOS, 1., Aracaju, 1999. Anais... Aracaju: EMBRAPA, 1999. p.47-56.

MONTENEGRO, A. A. T.; BANDEIRA, C.T.; LIMA, R. N. Distribuição do sistema radicular da acerola (Malpighia glabra L) sob sistema de irrigação por aspersão. In: CONGRESSO BRASILEIRO DE ENGENHARIA AGRÍCOLA, 30., Foz do Iguaçu, 2001. Anais... Foz do Iguaçu: $2001.1 \mathrm{CD}$.

NEVES, C. S. V. J. et al. Distribuição do sistema radicular de cultivares de aceroleira. Revista Brasileira de Fruticultura, Cruz das Almas, v.23, n.1, p.112-115, 2001.

PACE, C. A. M.; ARAÚJO, C. M. Estudo da distribuição do sistema radicular de porta-enxertos cítricos em solos podzolizados e sua relação com a formação de copas. In: CONGRESSO BRASILEIRO DE FRUTICULTURA, 8., Brasília, 1986. Anais... Brasília: Sociedade Brasileira de Fruticultura, 1986. p.199-205.

PARANÁ. (Estado). Secretaria da Agricultura e do Abastecimento. Manual técnico do subprograma de manejo e conservação do solo. Curitiba. 1989.

PAVAN, M. R. A. et al. Manual de análise química de solo e controle de qualidade. Londrina: IAPAR, 1992. 40p. (IAPAR. Circular, 76).

SCHOLZ, M. B .S.; STENZEL, N. M. C. Características físico-químicas de frutos de acerola (Malpighia spp) cultivados no Paraná. In: CONGRESSO BRASILEIRO DE FRUTICULTURA, 14., 1996. Curitiba. Anais... Curitiba: Sociedade Brasileira de Fruticultura, 1996. p.43.

STENZEL, N. M. C.; MOTTER, A. A. Cultura de acerola no estado do Paraná; pesquisa e extensão. In: SÃO JOSÉ, A. R.; ALVES, R. E. Acerola no Brasil: produção e mercado. Vitória da Conquista: UESB, 1995. p.130-132. 